\title{
Commentary: Bridging anticoagulation for mechanical heart valves: Haven't we crossed this bridge before?
}

John Bozinovski, MD, MSc

From the Division of Cardiac Surgery, University of British Columbia and the Royal Jubilee Hospital, Victoria, British Columbia, Canada.

Disclosures: Author has nothing to disclose with regard to commercial support.

Received for publication July 22, 2018; accepted for publication July 22, 2018; available ahead of print Aug 29, 2018.

Address for reprints: John Bozinovski, MD, MSc, 106-2020 Richmond Rd, Victoria, British Columbia V8R-6R5, Canada (E-mail: john.bozinovski@ubc.ca).

J Thorac Cardiovasc Surg 2019;158:204-5

$0022-5223 / \$ 36.00$

Copyright (c) 2018 by The American Association for Thoracic Surgery

https://doi.org/10.1016/j.jtcvs.2018.07.067

In this issue of the Journal, Tan and colleagues ${ }^{1}$ provide an opinion regarding anticoagulation bridging in patients with mechanical heart valves undergoing noncardiac surgical procedures. They outline the problem that operating on anticoagulated patients exposes them to risk of bleeding in excess of the risk posed were they not anticoagulated. Withholding anticoagulation to mitigate that risk, however, exposes patients to the risk of complications from thromboembolism.

Anticoagulation aside, surgical procedures and coexisting patient characteristics carry different risks of bleeding. Recommendations by Tan and colleagues ${ }^{1}$ take these varying risks into account by stratifying patients into low and high bleeding risk according to whether the surgery is a minor procedure or whether they have a low BleedMAP score. BleedMAP scores range from 0 to 4 , with a point for each of the following: a history of previous bleeding, mechanical mitral valve, active cancer, and thrombocytopenia. BleedMAP was developed in a different study that assessed patients who required anticoagulation for various indications. $^{2}$ Approximately a quarter of those indications were for mechanical prostheses. The value of using BleedMAP to stratify patients is thus limited but not wholly inapplicable.

In 2014, the American College of Cardiology (ACC) and the American Heart Association (AHA) published guidelines for the management of patients with valvular heart disease, and within it are contained recommendations for bridging therapy for patients with mechanical heart valves undergoing noncardiac surgery. ${ }^{3}$ In 2017, these guidelines were updated. ${ }^{4}$ The recommendations by Tan and colleagues $^{1}$ do not differ in any significant way from the ACC and AHA guidelines, with some exceptions. In patients at moderate to high risk (those with a mechanical mitral valve or those with a mechanical aortic valve and an additional risk factor, such as atrial fibrillation, previous thromboembolism, ejection fraction less than $35 \%$, or a

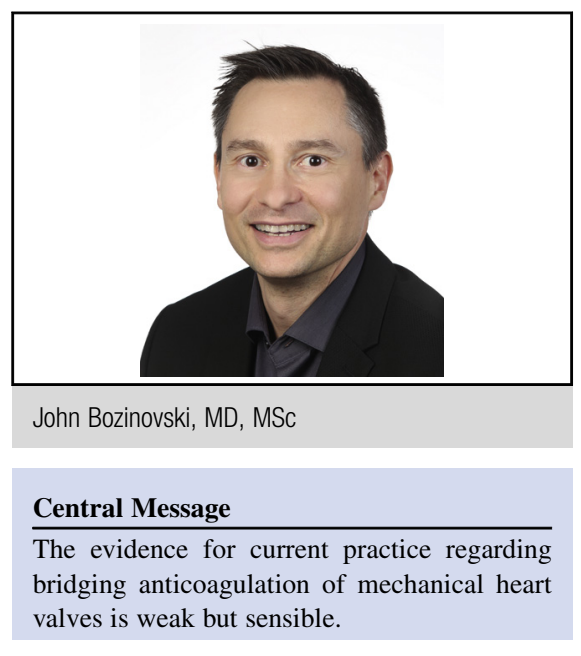

See Article page 200.

hypercoagulable state) undergoing major procedures, Tan and colleagues ${ }^{1}$ recommend resuming anticoagulation 12 to 24 hours postoperatively and beginning bridging therapy on postoperative day 2 , with the latter to continue until the lower range of therapeutic international normalized ratio is achieved for at least 24 hours. In comparison, the ACC and AHA guidelines recommend resuming anticoagulation 12 to 24 hours postoperatively but individually timing postoperative bridging according to risks of bleeding and thromboembolism. Tan and colleagues ${ }^{1}$ provided no new evidence to support varying from the ACC and AHA guidelines. The ACC and AHA guidelines provide a more individualized approach than that suggested in the article by Tan and colleagues. ${ }^{1}$ Otherwise, the recommendations are identical.

The updated ACC and AHA guideline stating that bridging should be used for high-risk patients is class IIa (conflicting evidence or divergence of opinion regarding usefulness), however, and is not based on high level of evidence (level C). The supporting evidence for the recommendation included 2 other societal guideline publications, ${ }^{5,6}$ a randomized study of bridging in atrial fibrillation, ${ }^{7}$ and a nonrandomized cohort study of bridging with various indications for anticoagulation. ${ }^{8}$ In the latter, overall thromboembolism incidence was $0.4 \%$ with bridging, but it was $1.7 \%$ in high-risk patients and $0 \%$ in low risk patients. Major bleeding occurred in $1.2 \%$ of patients overall. That study had no comparison group of nonbridged patients, which could have provided an estimate for 
bleeding hazard or thromboembolism protection afforded by bridging. Further, only 190 patients $(15 \%)$ had a mechanical valve as the indication for anticoagulation, again limiting the value of this study for a recommendation in that population.

\section{References}

1. Tan CW, Wall M, Rosengart TK, Ghanta RK. How to bridge? Management of anticoagulation in patients with mechanical heart valves undergoing noncardiac surgical procedures. J Thorac Cardiovasc Surg. 2019;158:200-3.

2. Tarfur AJ, Mcbane R II, Wysokinski WE, Litin S, Daniels P, Slusser J, et al. Predictors of major bleeding in peri-procedural anticoagulation management. $J$ Thromb Haemost. 2012;10:261-7.

3. Nishimura RA, Otto CM, Bonow RO, Carabello BA, Erwin JP III, Guyton RA, et al. American College of Cardiology/American Heart Association Task Force on Practice Guidelines. 2014 AHA/ACC guideline for the management of patients with valvular heart disease: a report of the American College of Cardiology/American Heart Association task force on practice guidelines. J Am Coll Cardiol. 2014; 63:e57-185. Erratum in: J Am Coll Cardiol. 2014;63:2489.

4. Nishimura RA, Otto CM, Bonow RO, Carabello BA, Erwin JP III, Fleisher LA, et al. 2017 AHA/ACC focused update of the 2014 AHA/ACC guideline for the management of patients with valvular heart disease: a report of the American College of Cardiology/American Heart Association task force on clinical practice guidelines. J Am Coll Cardiol. 2017;70:252-89.

5. Douketis JD, Spyropoulos AC, Spencer FA, Mayr M, Jaffer AK, Eckman MH, et al. Perioperative management of antithrombotic therapy: antithrombotic therapy and prevention of thrombosis, 9th ed: College of Chest Physicians evidence-based clinical practice guidelines. Chest. 2012;141(2 Suppl): e326S-50S

6. Task Force for Perioperative Cardiac Risk Assessment And Perioperative Cardiac Management In Non-cardiac Surgery of the European Society of Cardiology (ESC) and endorsed by the European Society of Anesthesiology (ESA), Poldermans D, Bax JJ, Boersma E, De Hert S, Eeckhout E, Gowkes G, et al. Guidelines for pre-operative cardiac risk assessment and perioperative cardiac management in non-cardiac surgery. Eur Heart J. 2009;30:2769-812.

7. Douketis JD, Spyropoulos AC, Kaatz A, Becker RC, Caprini JA, Dunn AS, et al BRIDGE Investigators. Perioperative bridging anticoagulation in patients with atrial fibrillation. $N$ Engl J Med. 2015;373:823-33.

8. Pengo V, Cucchini U, Denas G, Erba N, Guazzaloca G, La Rosa L, et al. Italian Federation of Centers for the Diagnosis of Thrombosis and Management of Antithrombotic Therapies (FCSA). Standardized low-molecular-weight heparin bridging regimen in outpatients on oral anticoagulants undergoing invasive procedure or surgery: an inception cohort management study. Circulation. 2009; 119:2920-7. 